\title{
SIMPLIFIED MEASUREMENTS
}

OF

\section{THE HEAT TRANSFER COEFFICIENT}

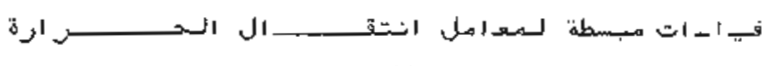

$\mathrm{BY}$

A. A. EL-HADIK

Mechanica! Engıneering Department,

University of El-Mansoura, Egypt.

\section{H. BARROW}

Mechanical Engineering Department, University of Liverpool, U. K.

$$
\begin{aligned}
& \text { النــلاصف : }
\end{aligned}
$$

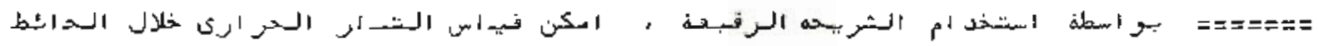

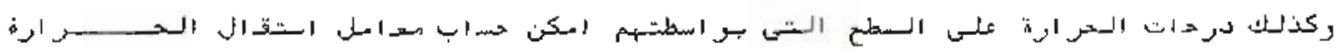

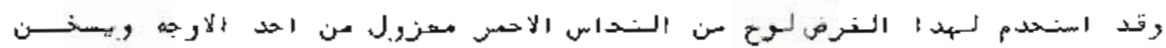

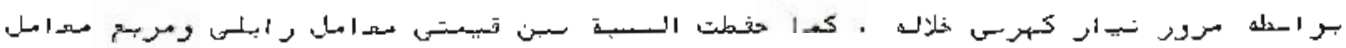

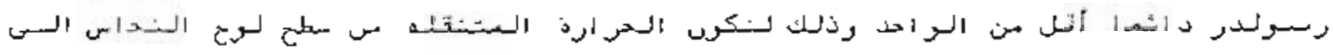

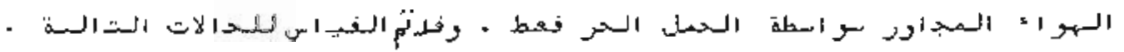

$$
\begin{aligned}
& 1
\end{aligned}
$$

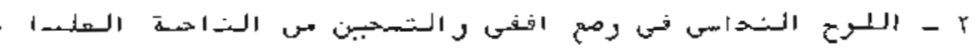

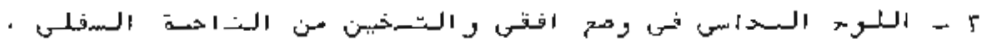

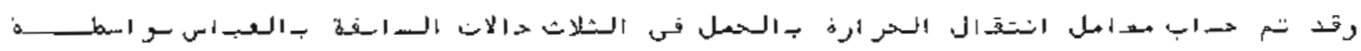

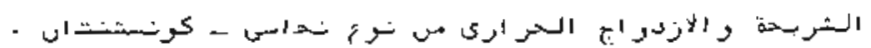

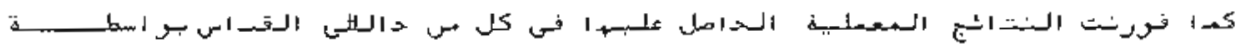

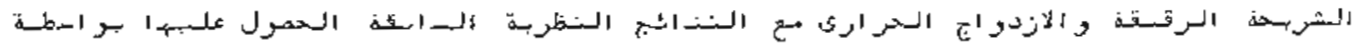

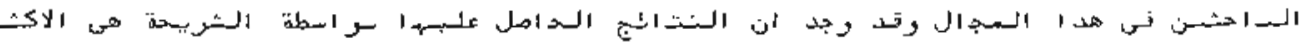

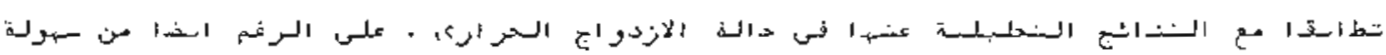

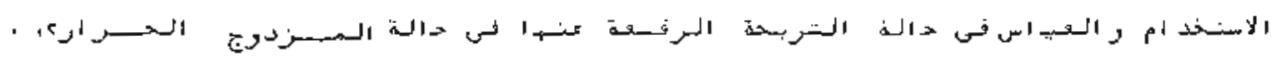

ABSTRACT-A micro-foll heat flow sensor is used to measure the heat llux and temperatures at a wall in order to determine the local heat transfer coefficient. An electrically heated copper plate is used for this purpose. The heat is considred to be transfered by free convection and the heat iransfer coefficient can be calculated accordingly.

Three cases were studied:

I. Vertical plate with one heated side

1. Horizontal plate with heated upper surface

iii. Horizontal plate with heated lower surface.

The results obtained by the use of micro-foil sensor as.

by the use of copper-constantan thermocouples were compared with results obtatneo theoretically by other investigators.tetrer agreement of heat transfer coefliclents obtained by foil measurements and theoretical analysis than those by thermocouples measurements, although the technique of foil measurements is simpler. 


\section{INTRODUCTION}

The micro-foil heat flow sensor is adifferential thermocouple type sensor which utilizes a thin foil type thermopile bonded to both sides of a known thermal barrier as shown in Fig. 1. The temperature difference across the thermal barrier is proportional to the heat flow through the sensor.

The function of heat flow sensor is to measure heat transfer (loss or gain) through a surface. It differentiates between the temperatures of two opposite sides of certain rigid materials and thereby allowing a direct measurement of the heat loss or gain through the material surface. The heat flow sensor is cemented onto a surface like strain gauges. The sensor is very thin and flexible and can be attached to flat or curved surfaces without damage to these surfaces. No special wiring, reference junctions, or signal conditioning are required. Reavout is accomplished by connecting the sensor to any direct reading microvoltmeter or recorder.

The goal of all convection heat transfer problems is to find the fluid temperature distribution as a function of geometry, flow conditions, and fluid properties. The wall heat transfer is found by applying Fourier's law of onduction for the thermal boundary layer next to the all, i.e.;

$$
q_{W}=-k \frac{d t}{d}-\frac{t}{y} \mid y=0
$$

The Newton's equation:

$$
q_{w}=h\left(t_{s}-t_{p o}\right)
$$

is then used to find the heat transfer coefficient h.

If the temperature distribution of the fluid close to the wall, $t(y)$, cannot be found analytically, then $q_{w}$ may be determined from experimental measurements. Micro-Foil technique can be used directly to measure the heat flux from a solid surface to a fluid and, consequently, the heat transfer coefficient is obtained by the use of Eq. 2.

For reasons of economy or scale, many engineering problems are concerned solely with free convection for example, cooling of electronic devices or domestic baseboard water and steam heaters. Even in designs of forced flow systems(e.g. pressurized water reactors), calculation of heat transfer by free convection is necessery for safety and protections considerations against burnout if the power moving the forced streams should fail. Finally, in geophysical problems, free convection in the dominant mode of heat transfer: atmospheric and oceanic motions are dominated by massive natural convection effects arising from special and temporal variations of solar heating. Therefore, the natural convection mode is chosen to check the validity of micro-foil measurements.

\section{EXPERIMENTAL RIG AND APPARATUS:}

Figure 2 shows the used experimental rig and the measuring instruments. The rig test section is a copper plate of $457.2 \mathrm{~mm}$ height $\times 254 \mathrm{~mm}$ width $\times 0.035$ $\mathrm{mm}$ thickness. The copper plate is cladded with a mica plate of $2.11 \mathrm{~mm}$ thickness. Then the copper plate is divided to eighteen strips of 24.4 . mm width each. The grooves between strips (of $1 \mathrm{~mm}$ width) are filled with mastic plaster, and sandedoff by smooth sand paper to utilize the copper plate as an electrical heater, see Fig. 2. The electric current passes through those serial strips to heat the copper plate. The electrical power supply is determined from the measurements of the potential voltage between the ends of the electrically heated copper plate by a voltmeter (kept constant at 1.95 volts). The electric resistance of the plate can 
De calcutalej by;

$$
R=\frac{S_{e} L}{z}=\frac{1.6 \times 10^{-8} \times 0.254 \times 18}{0.0244 \times 0.035 \times 10^{-3}}=2.086 \text { ohin }
$$

The electrical power for heating is ;

$$
\mathrm{Q}=\frac{\mathrm{V}^{2}}{\mathrm{R}^{-}}=\frac{(1.95)^{2}}{0.086}-44.39 \text { Watts. }
$$

As the plate surface area is $0.116 \mathrm{~m}^{2}(0.457 \mathrm{~m} \times 0.254 \mathrm{~m})$, then the electric heating per unit area is;

$$
q_{e}=\frac{Q}{A}=-\frac{44.39}{D} .116=382.68 \quad \mathrm{~W} / \mathrm{m}^{2}
$$

The surface tentperature (kept at less than $55^{\circ} \mathrm{C}$ ) is measured by copperconstantan thermocouple. The ambient room temperature is also recorded by a copper-constantan thermocouple. The heat loss.. by radiation from the copper plate is estumated by considering the emissivity of the polished copper is 0.045 and ambienc temperature of $22^{\circ} \mathrm{C}$, by;

$$
\begin{aligned}
q_{r}= & \sigma \varepsilon\left[\left(T_{s}\right)^{4}-\left(T_{\infty}\right)^{4}\right] \\
& =0.045 \times 5.6695 \times 10^{-8}\left[(55+273)^{4}-(22+273)^{4}\right]=10.21 \mathrm{~W} / \mathrm{m}^{2}
\end{aligned}
$$

Therefore, the heat loss. by radiation ccan't be neglected, and should be include-in the calculation of heat transfer coefficient.

The mica plate is also covered by plywood plate $12.5 \mathrm{~mm}$ in thickness. Then the thermal properties of the heated plate are:

\section{a) For Copper}

$$
\begin{aligned}
g_{0} & =8890 \mathrm{~kg} / \mathrm{m}^{3} \\
\mathrm{C}_{p} & =385.4 \mathrm{~J} / \mathrm{kg}^{\mathrm{k}} \\
\mathrm{k} & =11.24 \times 10^{-5} \mathrm{~m}^{2} / \mathrm{s} \\
\mathrm{k} & =385 \mathrm{~W} / \mathrm{mk} \\
x & =0.035 \mathrm{~mm}
\end{aligned}
$$

b) For Mica

$$
\begin{aligned}
& k=0.035 \mathrm{~W} / \mathrm{mk} \\
& x=2.11 \mathrm{num} \\
& \text { c) For Plywood }
\end{aligned}
$$

\section{c) For Plywood}


The thermal resistance of the heated plate may be calculated by:

$$
\mathrm{R}_{\mathrm{t}}=\left(\frac{\mathrm{x}}{\mathrm{k}}\right)_{\mathrm{c}}+\left(-\frac{\mathrm{x}}{\mathrm{k}}\right)_{\mathrm{m}}+\left(-\frac{\mathrm{x}}{\mathrm{k}}\right)_{\mathrm{w}}
$$

The heat loss by conduction from the $m$ ica side can be calculated by:

$$
q_{C}=-\frac{t_{s}-i^{2}}{R t}
$$

where, $t$, is the plywood surface temperatures, and is measured by using a copper-constantan thermocouple. Therefore, the heat loss. by conduction is computed to be $19.5 \mathrm{~W} / \mathrm{m}^{2}$, for $\mathrm{i}_{2}$ equal to $51.8{ }^{\circ} \mathrm{C}$.

Then the heat transferced by convection is estimated by substracting the summation of lieat losses by radiacion and conduction from the generated heat by electricicy, i.e.

$$
\begin{aligned}
q_{w} & =q_{e}-\left(q_{r}+q_{c}\right) \\
& =382.68-(1.0 .21+19.5)=352.27 \mathrm{~W} / \mathrm{m}^{2}
\end{aligned}
$$

The micro-foil heat flow sensor was used to simplify the measurement of heat flux. The completed sensor was placed in intimate contact with the copper plate surface where the heat transfer rates are to measured. The same energy passes through both the surface and the sensor attached with it. The thermal energy passes through a material, in this case the barrier due to the existance of a temperature gradient $\Delta t$. This temperature gradient is directly proportional to the magnitude of the thermal energy or, more precisely, the heat transfer rate.

The technical data of the used heat flow sensor (Rdf Corporation type 20457-1) are:

i) Calibrated sensitivity at $21^{\circ} \mathrm{C}$

ii) Electrical resistance

iii) Nominal thickness

iv) Heat capacity

v) Thermal resistance

vi) Emmsivity of the micro-foi!

$$
\begin{aligned}
& =0.393 \mu v / \mathrm{w} / \mathrm{m}^{2} \\
& =100 \mathrm{ohm} \\
& =0.102 \mathrm{~mm} \\
& =204 \mathrm{~J} / \mathrm{m}^{2} .{ }^{\circ} \mathrm{C} \\
& =0.0005{ }^{\circ} \mathrm{C} / \mathrm{W} / \mathrm{m}^{2} \\
& =0.05
\end{aligned}
$$

Therfore, the heat flux can be directly measured by the heat flow sensor, and subract the heat losses by radiation from the micro-foil, and the value is found equal to $353.66 \mathrm{~W} / \mathrm{m}^{2}$. This value is close. to the other value, which is calculated by using the thermocouple.

\section{RESULTS AND DISCUSSION:}

Figure 3 indicates the surface temperature and heat flux versus the time for the heated vertical plate. The surface temperatures were measured by both micro-foil sensor and the copper-constantan thermocouple. The temperatures measured by both methods were plotted and showed good agreement. However, the values of the surface temperature as measured by the micro-foil sensor were found higher than those values obtained by the thermocouple measurements. The reason is the different positions of the temperature sensing elements of both methods. The sensing element of the micro-foil is buried under the foil it self, while the thermocouple is bonded to the plate surface. It should be noted here that the steady state condition was reached within thirty minutes after energising starts, and recorded temperature difference is $35^{\circ} \mathrm{C}$. 
The values of the heat ilux ressured by the mico-toil were found iover than supplied electrical energy, because of the heat losses, by radiation and conduction in the last one.

: Sparrow and Gregg (1) recommended the following equation for laminer free convection from a vertical plate with constanr heat flux:

$$
N_{U L}=0.59\left(G_{r L} P_{r}\right)^{1 / 4} \text { for } 10^{9} G_{r L} P_{r} \quad 10^{4}
$$

The heat transfer coefficients calculated by Equation 3, were plotted in FIg. 4, together with those obtained from the micro-foli sensor measurements. The values of heat transfer coefficient obtained experimentally are higher than those calculated theoretically [Ref.l]. The experimental values of the heat transfer coefficients depend on the electric current value passing through the copper plate cross-section. While the calculated theoritical values depend on the fluid properties and plate dimensions. However, similar trend is obtained between the valwes obtained by both methods as shown in Fig. 4. Poor agreement was found between the data obtained by the copper-constantan thermocouple measurements and theortical data obtained by [Ref.1].

Figures 5 and 7 show the surface temperature and heat flux versus the time for horizontal plate heated upward, and downward respectively. The steady state conditions was reached for lower heated suriace case ina shorter time than that for the uppor heated surface. The figures also show the measurements oblained by the thermocouple are higher than those obtained by the micro-foil for the same reason mentioned earlier.

Figures 6 and 8 show the heat transfer coefficient values versus the tetemperature diflerence, for horizontal plates heated upward, and downward surface respectively. The measurements obtained by both micro-foil sensor and copper constantan thermocouple are compared with the following results:

$$
\begin{aligned}
& \text { 1) For horizontal plate with upper heated surface [See Ref.2]. } \\
& N_{U L}=0.15\left(R_{a L}\right)^{1 / 3}
\end{aligned}
$$

ii) For horizontal plate with lower heated surface [See Ref.3]:

$$
N_{U L}=0.27\left(R_{a L}\right)^{1 / 4}
$$

Where, $L$ is the characteristic length and can be represented by the average of the sum of length and widh of the rectangular plate.

The same trend was shown between the result obtaned by the microfoll and theoretical data (See Figs. 6 and 8). Poor agreement is observed for the results obtained by copper-constantan thermocouple measurements and theoretrcal calculations as shown in Figs.6 and 8.

\section{CONCLUSION:}

1- Heat flux can be simply and more accurately measured by using the micro-foil technique as compared with thermocouples measurements.

2- The measurements obtained by the micro-foil agree closely with the calculations obtained iheoretically

3- Poor agreement was abserved between the results obtained by the copper-constantan thermocouple and theoretical calculations. 
4- The surface temperature readings by using the micro-foil sensor or copper-constantan thermocouple are found in good agreement, while the heat transfer coefficients calculated by both micro-foil and thermo couple are found in poor agreement.

5- Stability of measurements by using the micro-foil is attained withn 30 minutes.

6- Whcro-foil sensor may be simple to use it in different applications.

NOMENCLATURE:

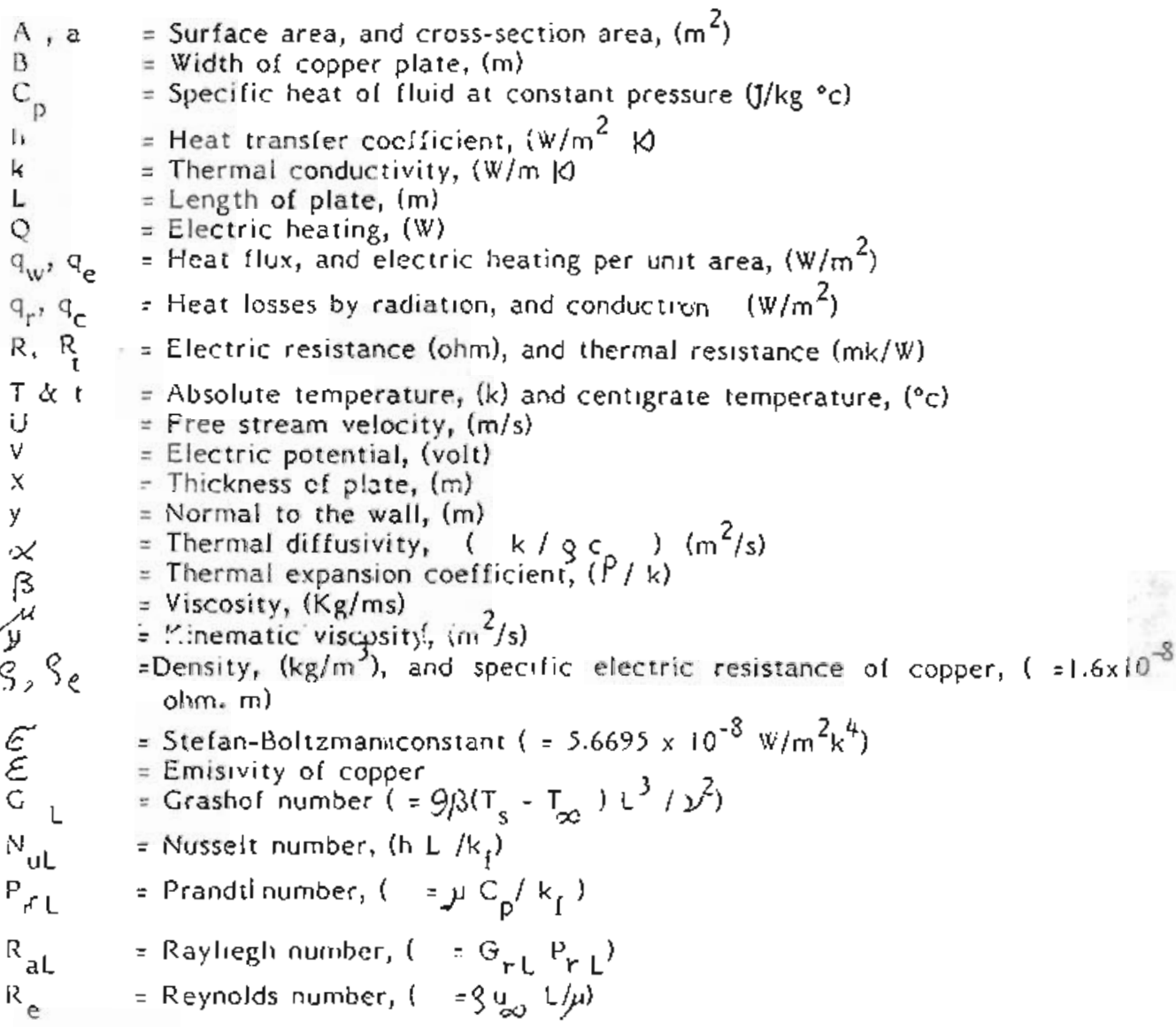

\section{Subscripts}

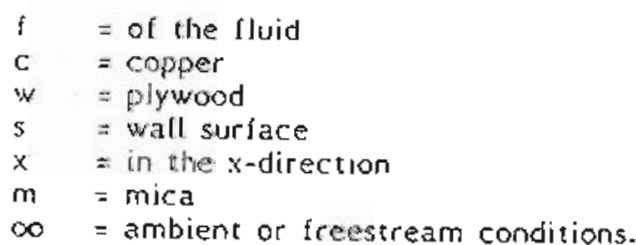


Mansoura Enqlneerlng Journal (JEJ) vol. 14, No. 2, Dec. 1989 M. 178

\section{REFERENCESE}

1- Sparrow, E.M., and Gregg, T.L., "Laminar Iree convection from vertical plane surface with untorm surface heat flux".

ASME Transactions of Heat Transfer, Vol. 78 pp. 435 - 440, Feb., 1956.

2- Fuj, $F_{1}$, and Imura., H. "Natural Convection heat transler from a place with arbitrary inclination".

Int. 1. Heac Mass Transfer, Vol. IS pp. 755 - 767, 1972.

3-Goldstein, R. J., Sparrow, E. W., and Jones, D.G. "Natural convection mass transfer adjacent to horizontal plates".

Int. J. Heat Mass Transter, Vol, 16, pp 1025 - 1035.

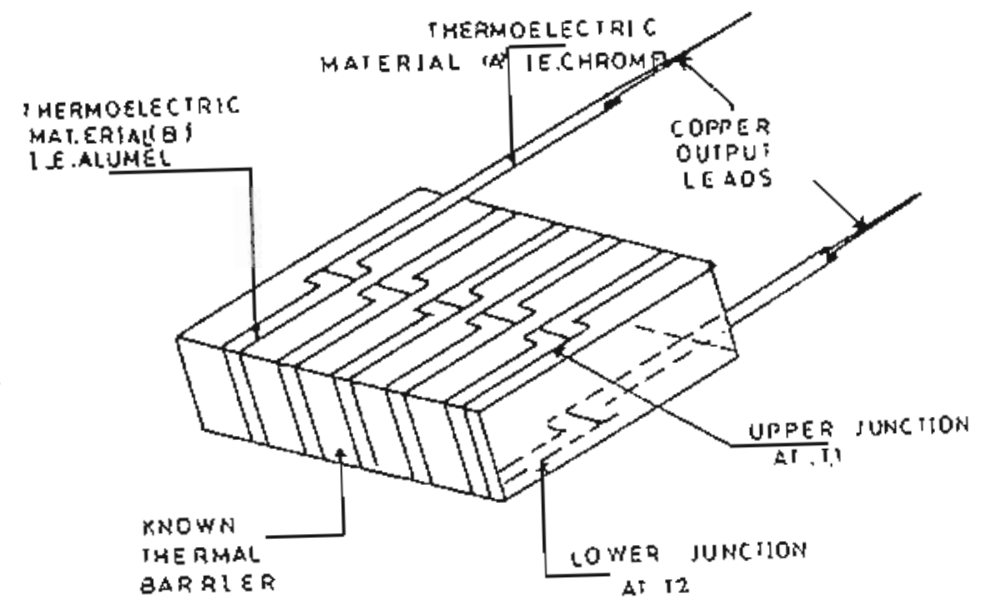

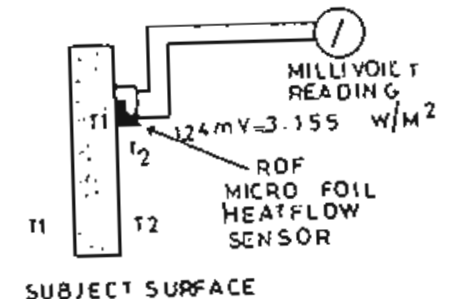

SUBJECT S UFFACE

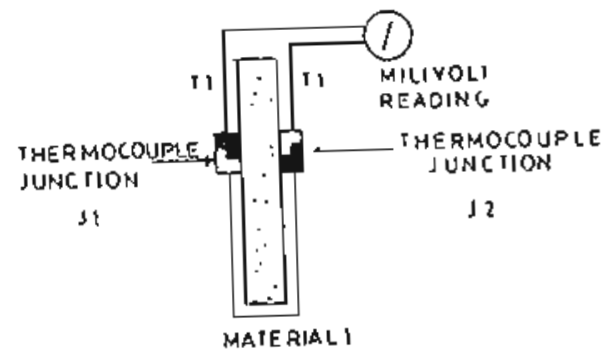

MAIE RIAL

FIG 1 HEAT FLOW SENSOR 

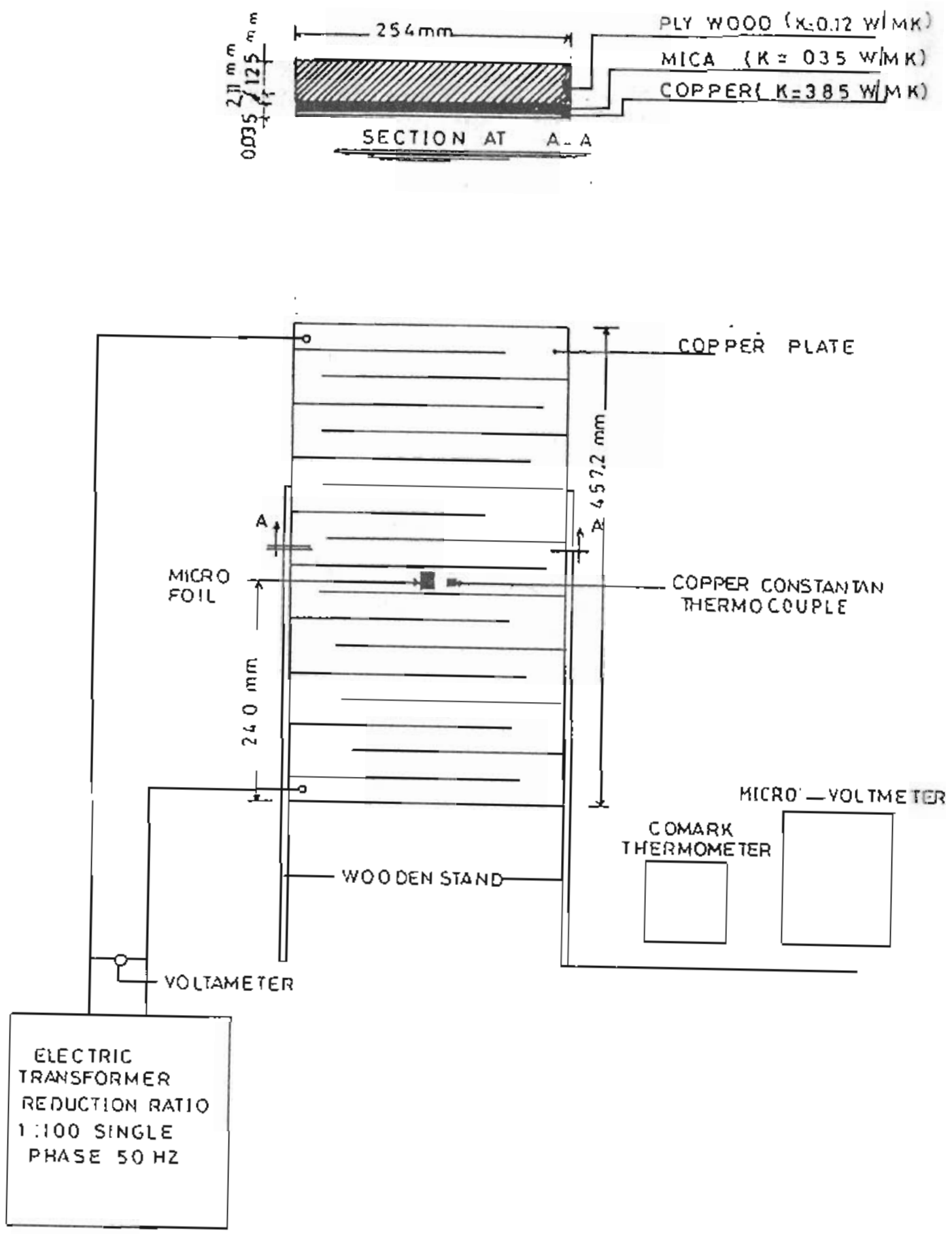


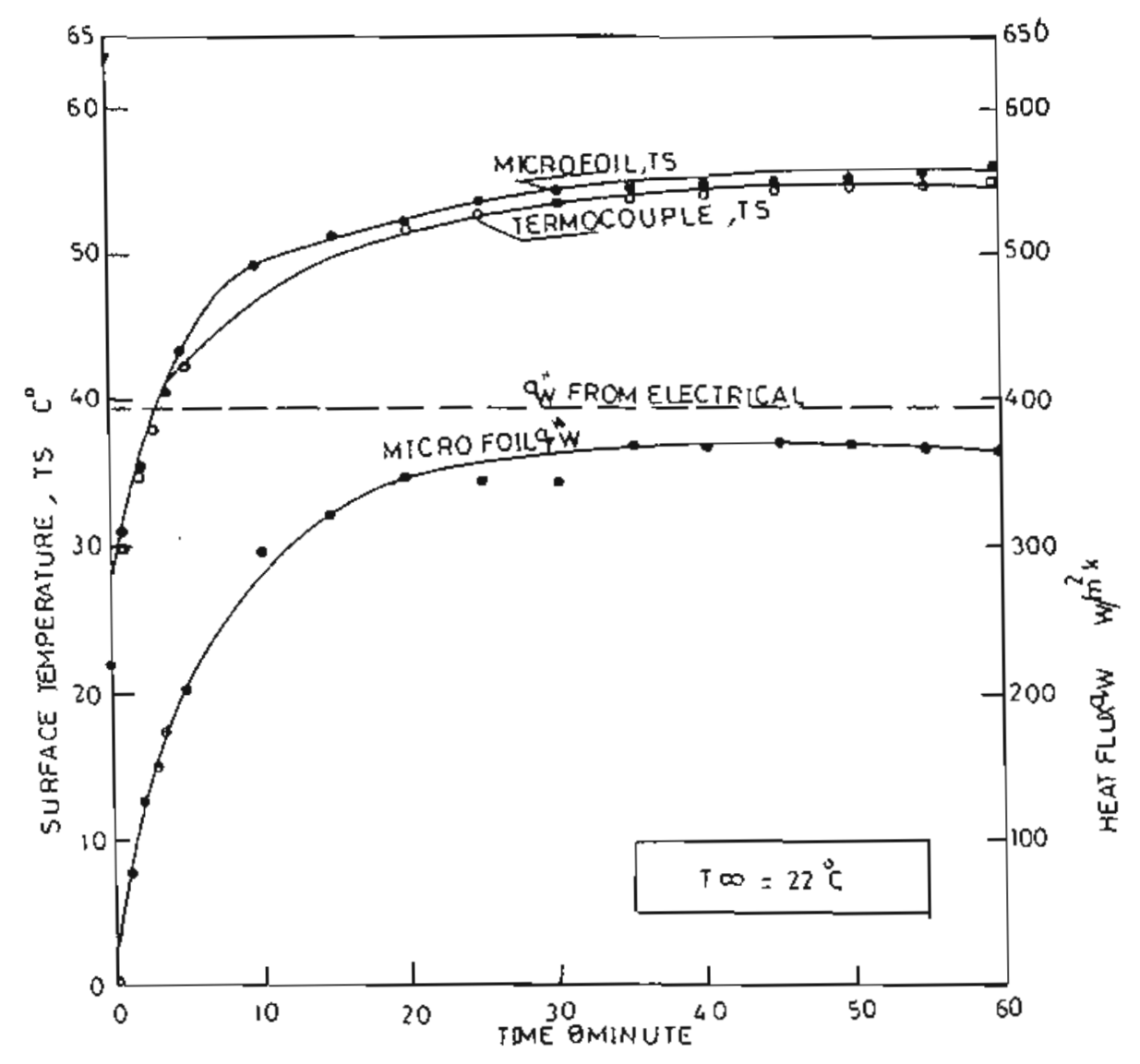

FIG 3 SURFACE TEMPERATURE AND HEAT FLUX FOR A VERTICAL PLATE 


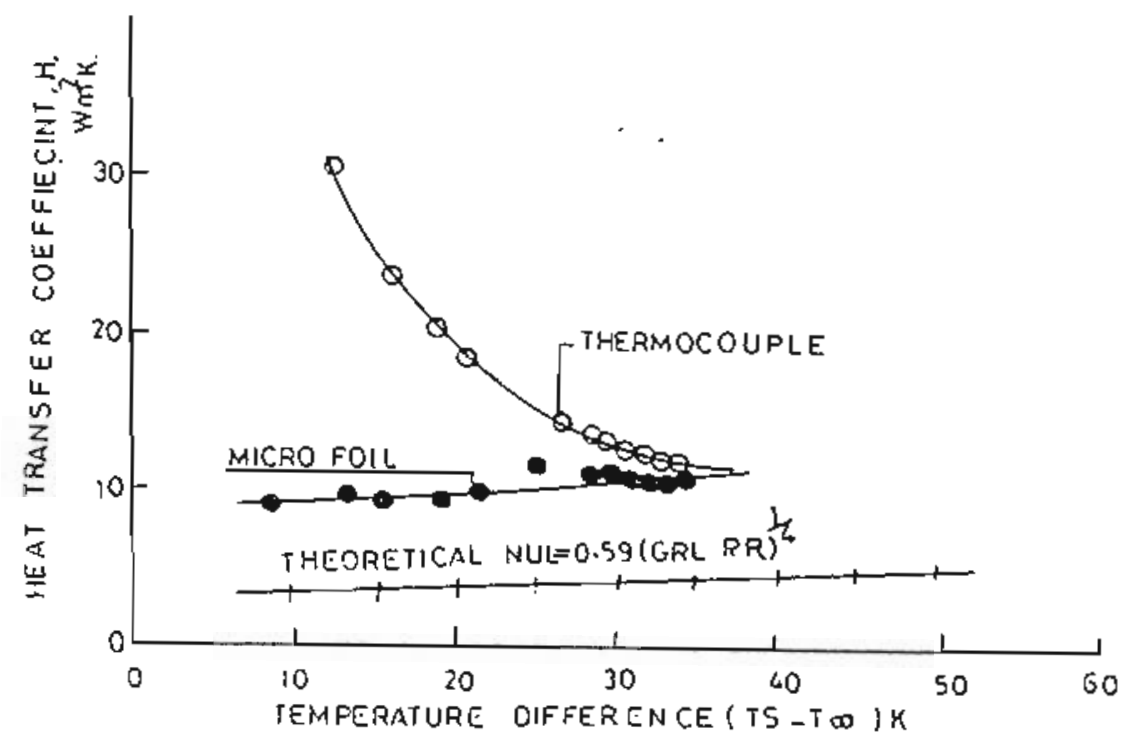

FIG 4 HEAT TRANSFER COEFFICIENT FOR A VERTICAL PLATE 


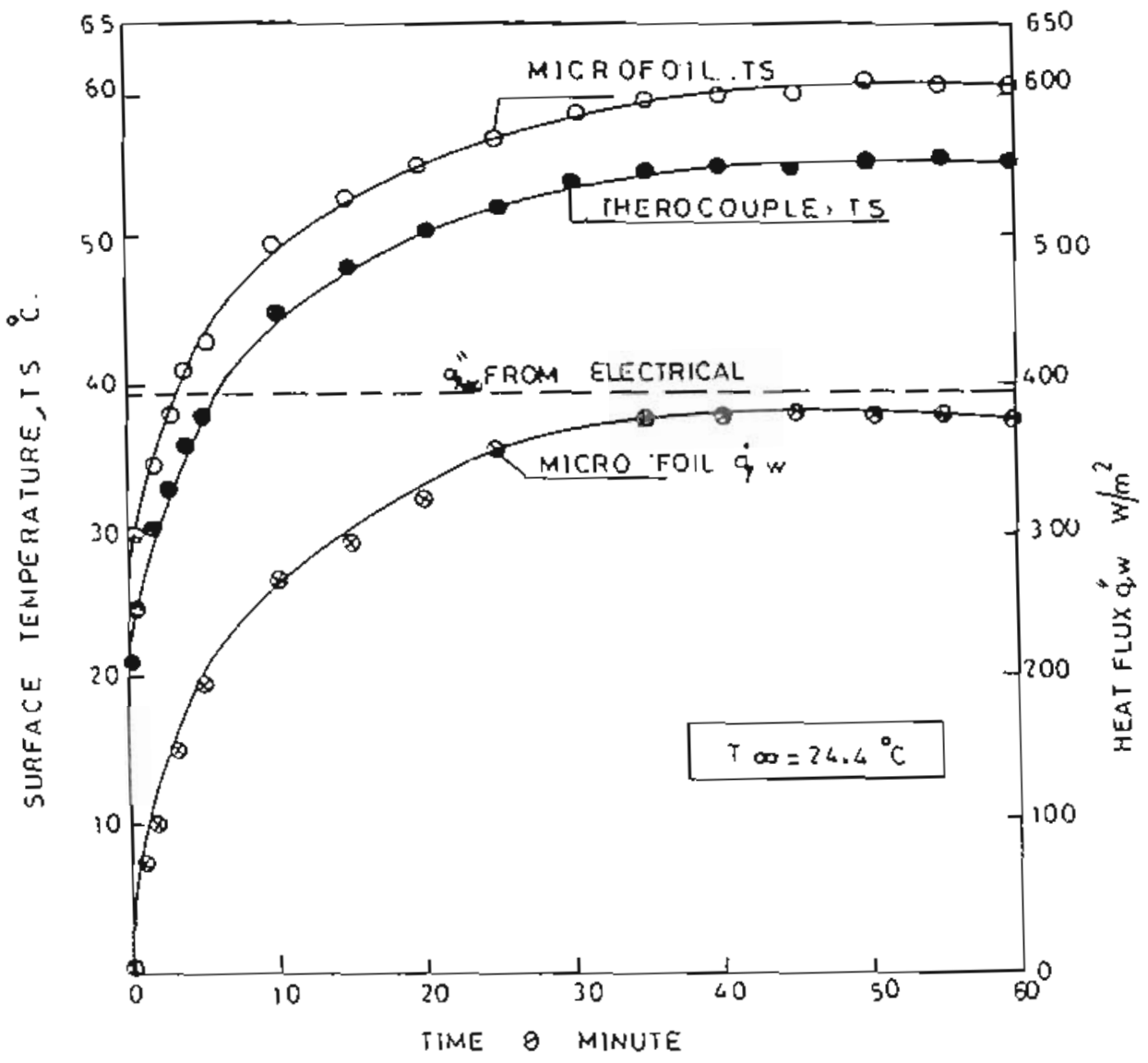

FIG 5 SURFACE TEMPERATURE AND HEAT FLUXFOR A HORIZONTAL PLATE WITH upper sureace heated 


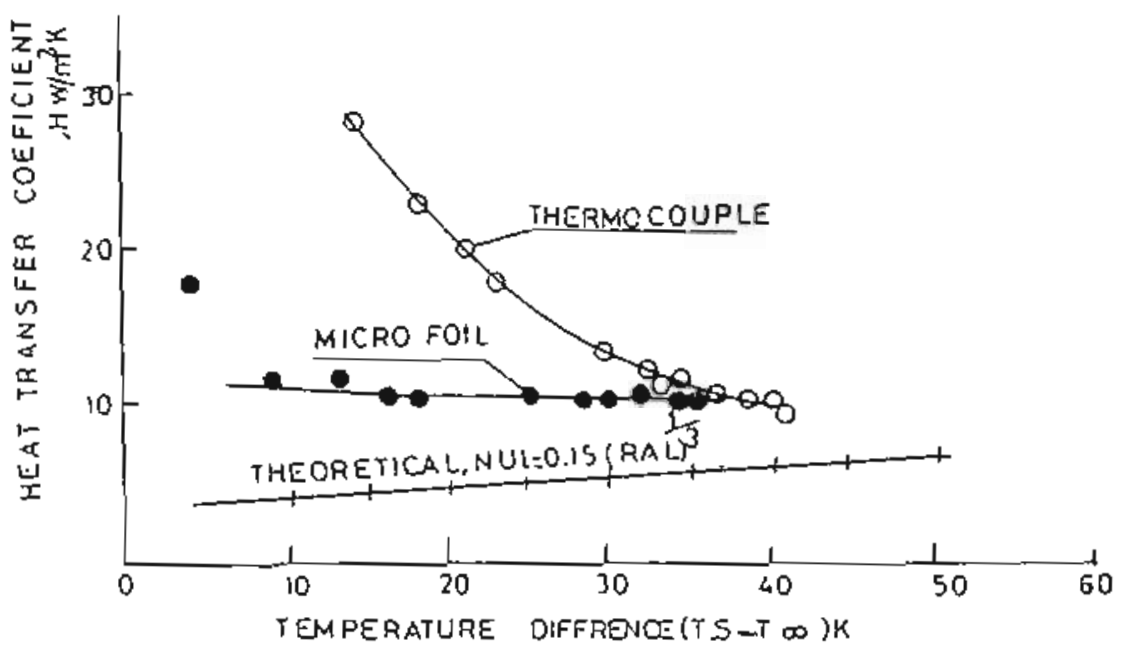

FIG 6 HEAT TRANSFER COEFFICIENT FOR A HORIZONTAL PLATE WITH UPPER

SURFACE HEATED 


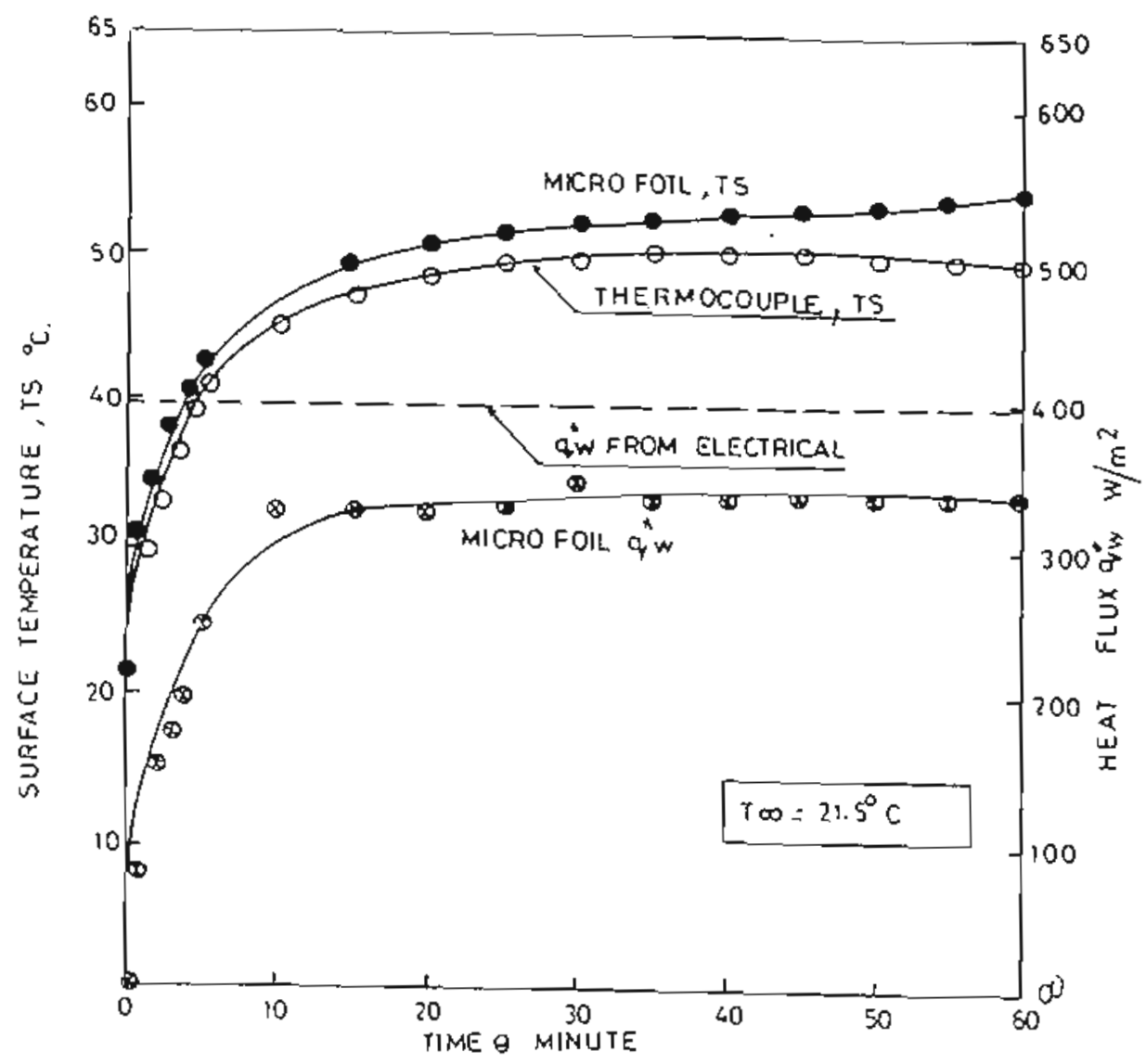

FIG.7 SURFACE TEMPERATURE AND HEAT FLUX FOR HORIZONTAL PLATE LOWER SURFACE HEATEO 


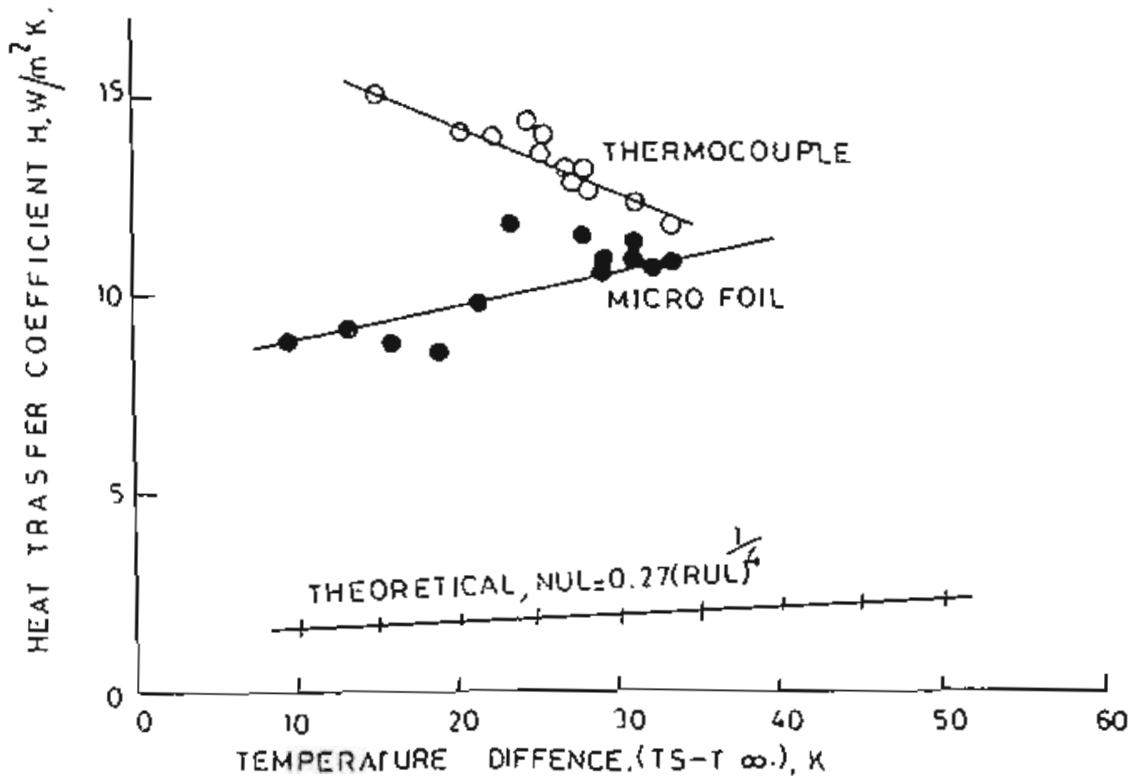

FIG 8 HEAT TRANSFER COEFFICIENT FOR HORIZONTAL PLATE WITH LOWER SURFACE HEATED 